\title{
Inversely Calibrated Curvilinear Artificial Neural Network Model for Simultaneous Assay of Ternary Cardiovascular Drug Mixture
}

\author{
Miranda F. Kamal ${ }^{* a}$, Marwa K. El Jamal ${ }^{\text {b }}$, Azza A. Gazy ${ }^{c}$ \\ ${ }^{a}$ Department of Pharmaceutical Analytical Chemistry, Faculty of Pharmacy, Damanhour University, Egypt \\ ${ }^{\mathrm{b}}$ Department of Pharmaceutical Analytical Chemistry and Drug Quality Control Beirut Arab University, Faculty of \\ Pharmacy, Department of Pharmaceutical Technology, Beirut, Lebanon \\ ${ }^{\mathrm{c}}$ Department of Pharmaceutical Analytical Chemistry and Drug Quality Control Beirut Arab University, Faculty of \\ Pharmacy, Department of Pharmaceutical Technology, Beirut, Lebanon
}

\begin{abstract}
Novel chemometric design, tailored for pre-clinical multiple drug screening, goals for bioanalytical future scope. A highly sensitive, non-linear multivariate Artificial Neural Network (ANN) is developed and applied for simultaneous spectrophotometric determination of three commonly concomitant cardiovascular drugs in a laboratory made mixtures and spiked human plasma samples. Ticagrelor, Irbesartan, and Hydrochlorothiazide have been simultaneously quantified in the curvilinear ranges of $0-30 \mu \mathrm{g} / \mathrm{mL}, 0-10 \mu \mathrm{g} / \mathrm{mL}$, and $0-3 \mu \mathrm{g} / \mathrm{mL}$ respectively. Highly overlapping Near UV absorption spectra of three drugs, in the region of $215-280 \mathrm{~nm}$, have been recorded 1$\mathrm{nm}$ range in synthetic ternary mixtures and trained iteratively. By inversely relating the concentration matrix $(x-$ block) with its corresponding absorption one ( $y$-block), gradient-descent back-propagation ANN calibration could be computed and optimized. All proposed mathematical modeling was manipulated using MATLAB ${ }^{\circledR} 2007$, reaching down to sixth order exponential Mean Square Error, MSE. To validate, an independent set of ternary synthetic mixtures has been constructed and examined, where excellent recovery results have been obtained. Furthermore, the application of the suggested model to varying ratios of synthetic ternary mixtures as well as spiked plasma samples has resulted in accurate, precise, and robust estimations with no background interference. ANN method was compared to a reference HPLC method; Student's $t$-test and $F$-variance ratio were calculated and showed the insignificant difference. This chemometric approach is an eco-friendly green assay, time-saving, and economic method. It initiates a pathway for clinical drug screening through affordable spectroscopic instrumentation.
\end{abstract}

Keywords: Artificial Intelligence; UV-Spectrophotometry; Ticagrelor; Irbesartan; Hydrochlorothiazide; spiked plasma; Non-linear range.

*Correspondence | Miranda F. Kamal; Department of Pharmaceutical Analytical Chemistry, Faculty of Pharmacy, Damanhour University, Egypt. Email: mirandafawzy@yahoo.com

Citation | Kamal MF, El Jamal MK, Gazy AA, 2020. Inversely Calibrated Curvilinear Artificial Neural Network Model for Simultaneous Assay of Ternary Cardiovascular Drug Mixture. Arch Pharm Sci ASU 4(2): 249-252

DOI: $10.21608 /$ aps. 2020.45025 .1042

Print ISSN: 2356-8380. Online ISSN: 2356-8399.

Received 22 October 2020. Accepted 26 December 2020.

Copyright: ${ }^{{ }} 2020$ Kamal et al. This is an open-access article licensed under a Creative Commons Attribution 4.0 International License (CC BY 4.0), which permits unrestricted use, distribution, and reproduction in any medium, provided the original author(s) and source are credited.

Published by: Ain Shams University, Faculty of Pharmacy

\section{INTRODUCTION}

Although Spectrometric drug assays are still the most applicable in quality control laboratories, their application is highly limited at the demand of high sensitivity and resolving much complicated overlaps. Intelligent spectral data analysis is no longer welfare for analysts [1]. Statistical data analysis, artificial intelligence, mathematical optimization, and machine learning are core competencies of chemometric trials for drug analysis in multicomponent complex 
formulations [2, 3]. Besides, being ecofriendly and green methods [4], Artificial neural networks (ANNs) or connectionist systems work like human brains, collect joined units or nodes known as artificial neurons, which handle the neurons in the human brain. Each junction, like synapses in real brains, can send a signal to other neurons. In ANN manipulations, the "signal" is data and each neuro signal is calculated by nonlinear function [5].

ANN abilities, as a machine learning computational mathematical pattern, is classified a subcategory of; function approximation, regression analysis, data processing, classification, sequential decision making, and reaching robotics control. Predictive analytics by the ANN calibration model can be efficiently applied for non-linear relationships, quantitative analysis of complex pharmaceutical matrices, and highly overlapped spectral data. Yet unresolved data sets could be identified using ANNs [6, 7]. ANNs have processed in vitro in vivo correlations [8, 9]. Networks have also been applied to pharmacokinetic data sets [10] and different pharmaceutical drug combinations have been assayed by ANNs [11-13].

Antihypertensive treatment reduces the risk of cardiovascular infarctions. Recent cardiac guidelines recommend combination therapy, rather than monotherapy [14]. Antithrombic agents synergize with antihypertensive combinations for long term treatment [15]. Alternatively, screening for potential drug-drug interactions, contraindications, or both, and by making therapeutic recommendations aimed at achieving optimal response without increasing the potential for adverse drug reactions, especially among elderly patients and those with multiple medical conditions. High demand for accurate and sensitive analysis as well as being economic, affordable, and green one.

The antihypertensive, Irbesartan (IRB), or 2-
butyl-3-[[2'-(1H-tetrazole-5-yl)[1,1'-biphenyl]-4yl]-methyl1-3-diazaspiro-[4,4]-non-1-en-4-one, (Fig. 1), is an angiotensin II blocker. It blocks AT1 receptors, reducing the effects of angiotensin II [16].

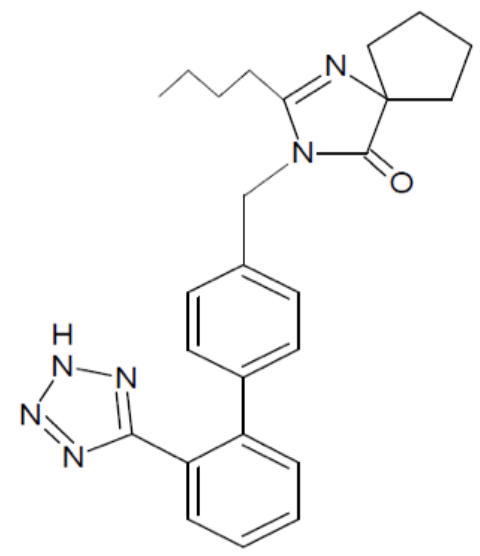

Fig. 1. Chemical Structure of Irbesartan

The antihypertensive, Hydrochlorothiazide (HCT), or 6-chloro-3,4-dihydro-2H-1,2,4benzothiadiazine-7-sulphonamide-1,1-dioxide,

(Fig. 2), promotes excretion of sodium and chloride through the kidney. It also prevents stone formation [16].

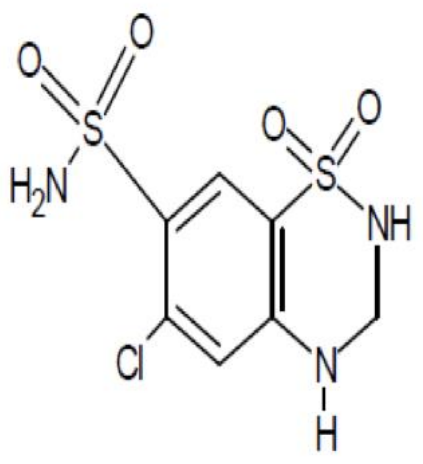

Fig. 2. Chemical Structure of Hydrochlorothiazide

The orally active antithrombic, Ticagrelor (TICA), or (1S,2S,3R,5S)-3-[7-\{[(1R,2S)-2-(3,4difluorophenyl)cyclopropyl]amino $\}-5$ (propylthio)-3H-[1,2,3]-triazolo 
pyrimidin-3-yl]-5-(2-hydroxyethoxycyclo

pentane-1,2-diol 2, was FDA approved 2011

(Fig. 3). It inhibits platelet activation and aggregation mediated by the P2Y12 ADPreceptor1. Thus it lowers the rate of thrombotic cardiovascular infarction in patients with acute coronary syndrome [16].

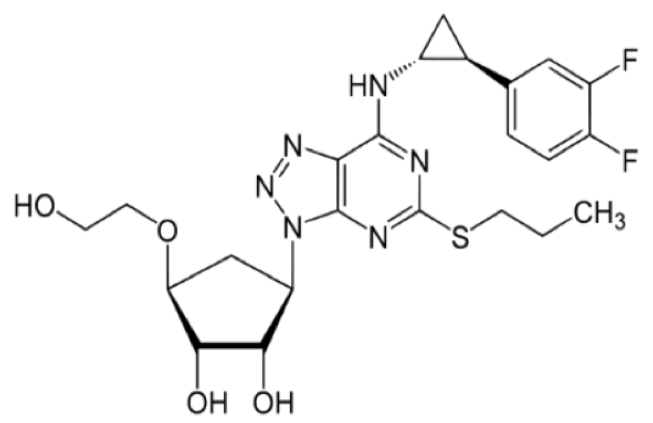

Fig. 3. Chemical Structure of Ticagrelor

Literature states different analytical techniques for IRB determination using UVSpectrophotometry [17], and RP-HPLC [18]. Also, determined in human plasma by LC [19]. In presence of HCT, IRB has been determined spectrophotometrically [20], RP-HPLC [21, 22], and thermometrically [23]. Both HCT and IRB mixture was simultaneously quantified in biological fluids [24, 25]. Other IRB combinations have been assayed chromatographically [26, 27]. HCT, as a single component, has been determined UVspectrophotometrically [28], and LC [29]. HCT combination mixtures have been resolved either by LC [30] or thermometrically [31]. TICA has been assayed by UV-spectrophotometry [32]. As well as in plasma samples, it has been determined by LC-MS [33] and LC-MS-MS [34].

Literature reveals the simultaneous determination of IRB, HCT, and TICA ternary mixtures by RP-LC, and spectrophotometrically $[35,36]$. Meanwhile, the present work is the first to use iterative neural modeling for the three drugs' non-linear UV spectra, starting at zero $\mu \mathrm{g} / \mathrm{mL}$ quantification. The proposed model permits their determination in plasma samples spectrophotometrically without prior chromatographic separation, coming over the latter references.

\section{MATERIALS AND METHODS}

\subsection{Apparatus}

Thermo Spectronic UV-Vis spectrophotometer connected to Harvest computer system was used. Absorption spectra were measured in $1-\mathrm{cm}$ quartz cells. The absorbance data was displayed on EXCEL sheets and processed using MATLAB software.

\subsection{Materials and Reagents}

TICA was purchased from AstraZeneca. IRB and HCT were obtained from Accord-UK LTD, London.

\subsection{Standard Solutions}

Standard stock solutions, $100 \mu \mathrm{g} / \mathrm{mL}$, of each of TICA, IRB, and HCT were separately and accurately prepared in ethanol. Different aliquots were micropippetted from each stock solution to form a set of 90 standard ternary mixtures. A wide range of drug concentrations was stated in each synthetic mixture as in Table 1.

\subsection{Preparation of Spiked Plasma Samples}

Plasma from the blood bank (Biuret, Lebanon) was purchased and kept at $-20{ }^{\circ} \mathrm{C}$. Gentle heating and shaking were required at the time of analysis. K3 EDTA was added for protein precipitation. Here, $400 \mu \mathrm{L}$ of plasma samples were taken separately into a serial tube and vortexed for 3 min after being spiked with ternary mixture solution (in ethanol) at different concentration ratios. Then, the total amount of ethanol was brought to $1 \mathrm{~mL}$ by evaporation under a stream of nitrogen and vortexed for 3 $\min$. The mixtures were centrifuged for $20 \mathrm{~min}$ at $4500 \mathrm{rpm}$, the supernatants were carefully 
separated using a Pasteur pipette and analyzed.

Table 1. The ANN training set; 90 different ternary mixture solutions of TICA, IRB and HCT

\begin{tabular}{|c|c|c|c|c|c|c|c|}
\hline Set No. & $\begin{array}{c}\text { TICA } \\
\mu \mathrm{g} / \mathrm{mL} \\
\end{array}$ & $\begin{array}{c}\text { IRB } \\
\mu \mathrm{g} / \mathrm{mL}\end{array}$ & $\begin{array}{c}\text { HCT } \\
\mu \mathrm{g} / \mathrm{mL}\end{array}$ & $\begin{array}{l}\text { Set } \\
\text { No. } \\
\end{array}$ & $\begin{array}{c}\text { TICA } \\
\mu \mathrm{g} / \mathrm{mL}\end{array}$ & $\begin{array}{c}\text { IRB } \\
\mu \mathrm{g} / \mathrm{mL}\end{array}$ & $\begin{array}{c}\mathrm{HCT} \\
\mu \mathrm{g} / \mathrm{mL}\end{array}$ \\
\hline 1 & 5 & 1 & 10 & 46 & 25 & 0 & 9 \\
\hline 2 & 5 & 1.5 & 9 & 47 & 25 & 1 & 8 \\
\hline 3 & 5 & 2 & 8 & 48 & 25 & 1.5 & 7 \\
\hline 4 & 5 & 2.5 & 7 & 49 & 25 & 2 & 6 \\
\hline 5 & 5 & 3 & 6 & $\mathbf{5 0}$ & 25 & 3 & 5 \\
\hline 6 & 5 & 0 & 5 & 51 & 30 & 1 & 4 \\
\hline 7 & 5 & 1 & 4 & 52 & 30 & 1.5 & 3 \\
\hline 8 & 5 & 1.5 & 3 & 53 & 30 & 2 & 2 \\
\hline 9 & 5 & 2 & 2 & 54 & 30 & 2.5 & 1 \\
\hline 10 & 5 & 3 & 1 & 55 & 30 & 3 & 0 \\
\hline 11 & 10 & 1 & 0 & 56 & 30 & 0 & 10 \\
\hline 12 & 10 & 1.5 & 10 & 57 & 30 & 1 & 9 \\
\hline 13 & 10 & 2 & 9 & 58 & 30 & 1.5 & 8 \\
\hline 14 & 10 & 2.5 & 8 & 59 & 30 & 2 & 7 \\
\hline 15 & 10 & 3 & 7 & 60 & 0 & 2.5 & 6 \\
\hline 16 & 10 & 0 & 6 & 61 & 3 & 3 & 5 \\
\hline 17 & 10 & 1 & 5 & 62 & 3 & 0 & 4 \\
\hline 18 & 10 & 1.5 & 4 & 63 & 3 & 1 & 3 \\
\hline 19 & 10 & 2 & 3 & 64 & 3 & 1.5 & 2 \\
\hline 20 & 10 & 3 & 2 & 65 & 3 & 2 & 1 \\
\hline 21 & 15 & 1 & 1 & 66 & 3 & 2.5 & 0 \\
\hline 22 & 15 & 1.5 & 0 & 67 & 3 & 3 & 10 \\
\hline 23 & 0 & 2 & 10 & 68 & 3 & 0 & 9 \\
\hline 24 & 15 & 2.5 & 9 & 69 & 3 & 1 & 8 \\
\hline 25 & 15 & 3 & 8 & 70 & 3 & 1.5 & 7 \\
\hline 26 & 15 & 0 & 7 & 71 & 23 & 2 & 6 \\
\hline 27 & 15 & 1 & 6 & 72 & 23 & 2.5 & 5 \\
\hline 28 & 15 & 1.5 & 5 & 73 & 23 & 3 & 4 \\
\hline 29 & 15 & 2 & 4 & 74 & 23 & 0 & 3 \\
\hline 30 & 15 & 3 & 3 & 75 & 23 & 1 & 2 \\
\hline 31 & 20 & 1 & 2 & 76 & 23 & 1.5 & 1 \\
\hline 32 & 20 & 1.5 & 1 & 77 & 23 & 2 & 0 \\
\hline 33 & 20 & 2 & 0 & 78 & 23 & 2.5 & 10 \\
\hline 34 & 20 & 2.5 & 10 & 79 & 23 & 3 & 9 \\
\hline 35 & 20 & 3 & 9 & 80 & 23 & 0 & 8 \\
\hline 36 & 20 & 0 & 8 & 81 & 12 & 1 & 7 \\
\hline 37 & 20 & 1 & 7 & 82 & 12 & 1.5 & 6 \\
\hline 38 & 20 & 1.5 & 6 & 83 & 12 & 2 & 5 \\
\hline 39 & 20 & 2 & 5 & 84 & 12 & 2.5 & 4 \\
\hline 40 & 20 & 3 & 4 & 85 & 12 & 3 & 3 \\
\hline 41 & 25 & 1 & 3 & 86 & 12 & 0 & 2 \\
\hline 42 & 25 & 1.5 & 2 & 87 & 12 & 1 & 1 \\
\hline 43 & 25 & 2 & 1 & 88 & 12 & 1.5 & 0 \\
\hline 44 & 25 & 2.5 & 0 & 89 & 12 & 2 & 10 \\
\hline
\end{tabular}


3

10

90

12

2.5

ANN; Artificial Neural Network - TICA; Ticagrelor - IRB; Irbesartan - HCT; Hydrochlorothiazide addition of organic solvent + centrifugation + evaporation + addition of mobile phase)

\subsection{Construction of ANN Model}

Modeling access related both the concentrations of the ternary drug mixture (TICA, IRB, and HCT) and their corresponding absorbance values, in a wide non-linear range, independent of Beer's law. As a start, the multivariate ternary model was constructed based on a training set; 90 mixtures of standard drugs, followed by ANN optimization through a predictive five-level three-factor design. These 135 sample mixtures were split into 90 training mixtures (for building the models) and 45 validation mixtures (for measuring the predictive power of the model). The concentration set; training set, of 90 synthetic mixtures containing TICA, IRB, and HCT in the concentration range of $0-30 \mu \mathrm{g} / \mathrm{mL}, 0-10 \mu \mathrm{g} / \mathrm{mL}$, and $0-3 \mu \mathrm{g} / \mathrm{mL}$, respectively in ethanol were prepared. Their absorption spectra (A; x-block, conc.; y-block) of the mixture set were plotted and recorded (66wavelength points) in the spectral range of 215280 nm (Fig. 4).

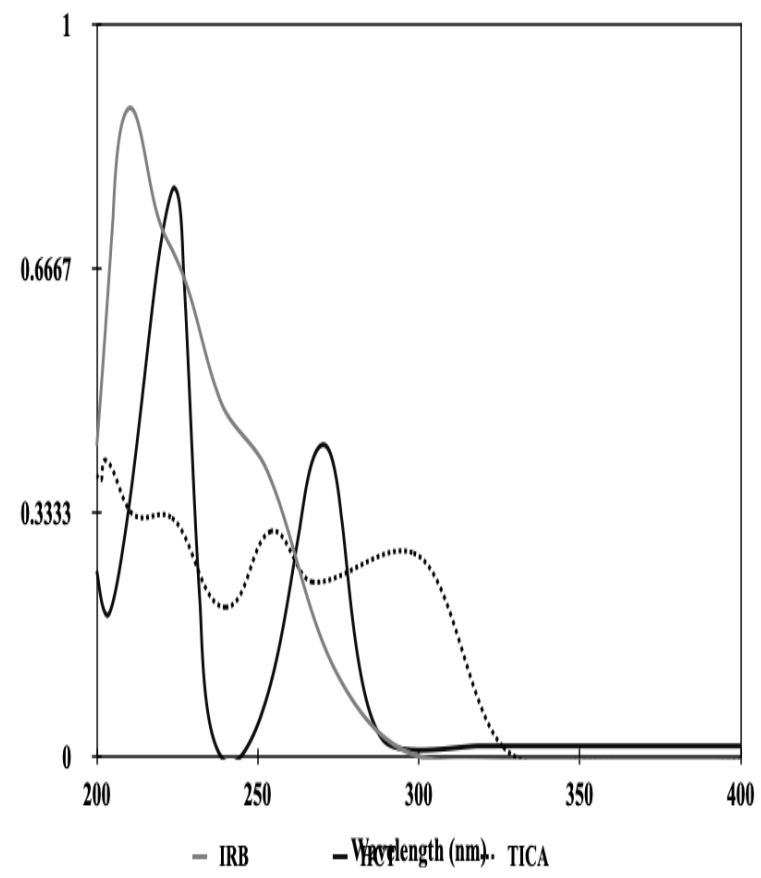

Fig. 4. Absorption curves of $9 \mu \mathrm{g} . \mathrm{mL}^{-1}$ TICA (....), 6 $\mu \mathrm{g} . \mathrm{mL}^{-1}$ HCT (_ black line), and $1.25 \mu \mathrm{g} . \mathrm{mL}^{-1}$ IRB (grey line) in ethanol

ANN chemometric calibration was computed in a non-linear relationship between triple vector (3 concentration set) and their corresponding A readings (y-block).

\subsection{ANN Optimization}

Various topological networks were iteratively run for optimization. A training network of 120 neurons in the input layer, 50 neurons in hidden layers, and three outputs for the calibration and prediction steps was found to be suitable for the construction of ANN calibration for the simultaneous quantitative prediction of the three co-administrated drugs in laboratory prepared mixtures and spiked plasma samples.

\subsection{Study for ANN Optimization parameters}

Transfer function; it is chosen according to the nature of trained data. Being non-linear (A vs conc). Correlation, Log sigmoid activation function has been used for hidden and output layers.

Gradient descent training neural network has been backpropagated (Fig. 5). Thus, the mean square error, MSE, between the network output and the actual values was minimized. 


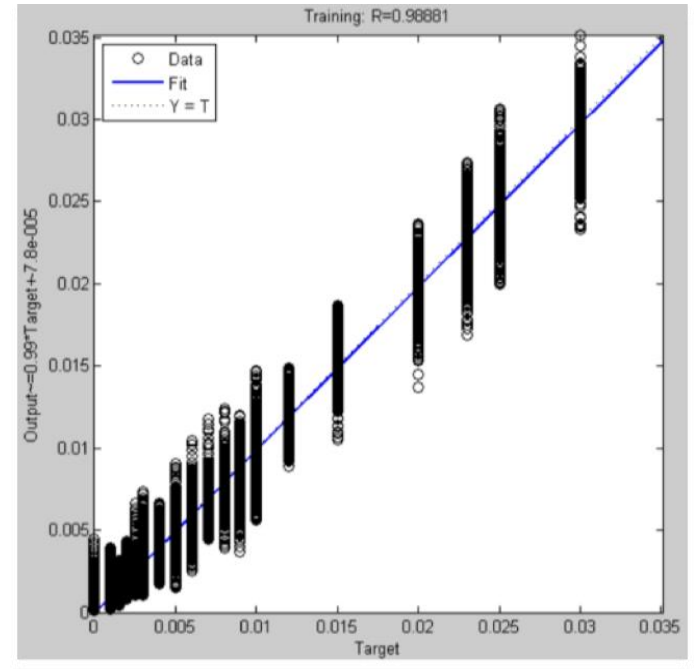

Fig. 5. Training Plot of the proposed Artificial Neural Network

The learning rate initialized for the network was 0.5. The learning coefficient (Lc) masters the connection weights variation during the learning phase. Hidden neurons number (HNN) affected the convoluted performance of the output error function during the learning process.

Different training functions showed no significant difference in their performance (i.e. root mean square error of prediction (RMSEP) was not affected). M-training algorithm was chosen.

Iterative propagations were run to optimize regression of the targeted values versus the real outputs. As shown, Fig. 6 is an illustrative regression plot taken for one of these run propagations.

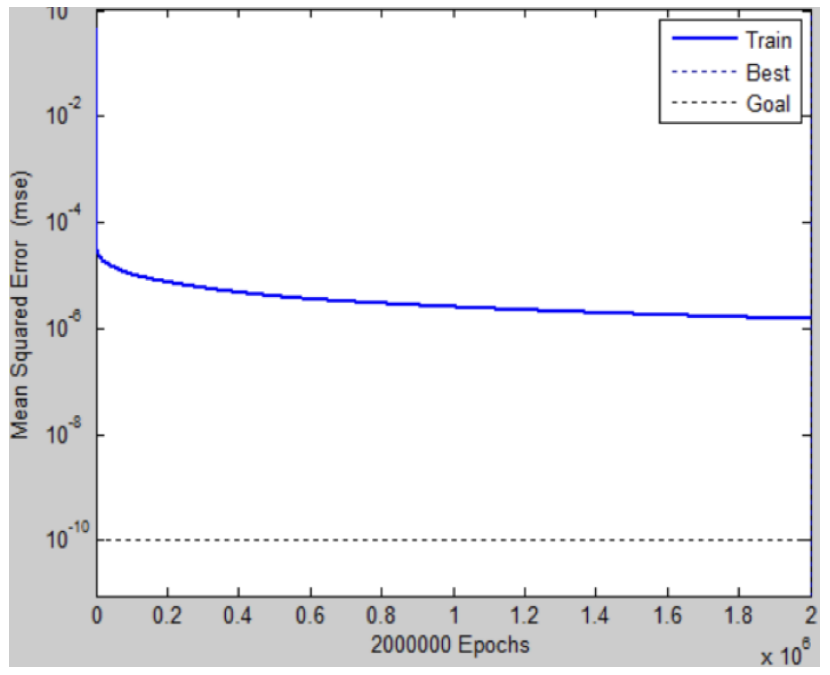

Fig. 6. Regression Plot of the proposed Artificial Neural Network

Upon application of an optimized calibration model, Mean Square Error (MSE) and network Epochs were correlated. The least MSE recorded a value of $1.49 \times 10^{-6}$ as shown in the "Performance Plot" of the proposed network (Fig. 7).

\section{Results and Discussion}

\subsection{Method Validation}

To validate the predictability of the present model, ANN was run to estimate the concentration of three analytes in 45 synthetic mixtures (validation set) containing different ratios of drugs within the previously trained ranges. Validation and training sets are independent. Satisfactory results have been obtained for all mixtures. Mean recovery results and relative standard deviations are shown in Table 2. 


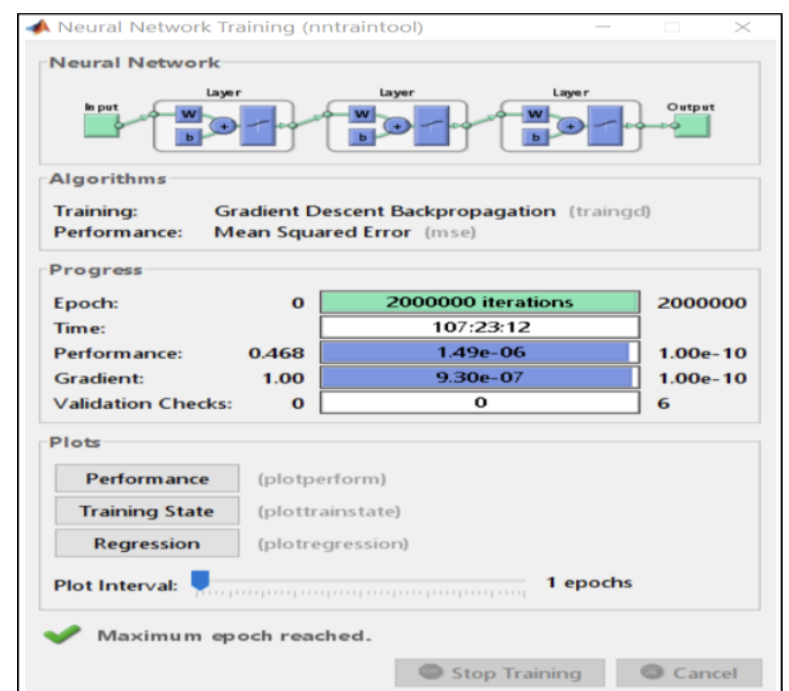

Fig. 7. Performance Plot of the proposed Artificial Neural Network

\subsection{Application}

Table 2. Recovery results of ANN validation set; 45 synthetic ternary mixtures of TICA, IRB and HCT

\subsubsection{Analysis of Laboratory made mixtures}

Laboratory made mixtures were prepared and analyzed by the proposed ANN method. The assay results revealed satisfactory accuracy and precision as indicated from \% recovery, SD, and RSD \% (Table 3). This table also represents a statistical comparison between the assay of TICA, IRB, and HCT in their synthetic mixtures by the proposed assisted ANN method and a developed HPLC method [35], using the student's t-test and the variance ratio F-test. Since the calculated $\mathrm{t}-$ and $\mathrm{F}$ - values for each drug did not exceed the theoretical ones $[37,38]$, this indicated no significant difference between the applied methods for determination of the three drugs in a laboratory made mixtures.

\begin{tabular}{|c|c|c|c|c|c|c|c|c|c|}
\hline \multirow{3}{*}{ Set No. } & \multirow{2}{*}{\multicolumn{6}{|c|}{ Concentration $(\mu \mathrm{g} / \mathrm{mL})$}} & \multirow{2}{*}{\multicolumn{3}{|c|}{ Recovery (\%) }} \\
\hline & & & & & edicted & & & & \\
\hline & TICA & IRB & HCT & TICA & IRB & HCT & TICA & IRB & HCT \\
\hline 1 & 5 & 1 & 10 & 5.1 & 1 & 10 & 102 & 100 & 100 \\
\hline 2 & 5 & 2 & 8 & 5 & 2.1 & 8 & 100 & 105 & 100 \\
\hline 3 & 5 & 3 & 6 & 5.1 & 3.1 & 6 & 102 & 103.3 & 100 \\
\hline 4 & 5 & 1 & 4 & 5 & 1 & 3.9 & 100 & 100 & 97.5 \\
\hline 5 & 5 & 2 & 2 & 5 & 1.9 & 2.1 & 100 & 95 & 105 \\
\hline 6 & 10 & 1.5 & 10 & 10 & 1.4 & 10 & 100 & 93.3 & 100 \\
\hline 7 & 10 & 2.5 & 8 & 10 & 2.5 & 8 & 100 & 100 & 100 \\
\hline 8 & 10 & 0 & 6 & 9.7 & 0 & 6 & 97 & 100 & 100 \\
\hline 9 & 10 & 1.5 & 4 & 10 & 1.5 & 3.8 & 100 & 100 & 95 \\
\hline 10 & 10 & 3 & 2 & 10.3 & 2.9 & 2 & 103 & 96.7 & 100 \\
\hline 11 & 15 & 1.5 & 0 & 15 & 1.5 & 0 & 100 & 100 & 100 \\
\hline 12 & 15 & 2.5 & 9 & 14.9 & 2.5 & 8.6 & 99.3 & 100 & 95.6 \\
\hline 13 & 15 & 0 & 7 & 15 & 0 & 7 & 100 & 100 & 100 \\
\hline 14 & 15 & 1.5 & 5 & 15 & 1.5 & 5 & 100 & 100 & 100 \\
\hline 15 & 15 & 3 & 3 & 14.5 & 3 & 3 & 96.7 & 100 & 100 \\
\hline 16 & 20 & 1.5 & 1 & 20.6 & 1.5 & 1 & 103 & 100 & 100 \\
\hline 17 & 20 & 2.5 & 10 & 20.1 & 2.6 & 9.7 & 100.5 & 104 & 97 \\
\hline 18 & 20 & 0 & 8 & 20 & 0 & 7.9 & 100 & 100 & 98.7 \\
\hline 19 & 20 & 1.5 & 6 & 20 & 1.5 & 6 & 100 & 100 & 100 \\
\hline 20 & 20 & 3 & 4 & 20.2 & 3.2 & 4.1 & 101 & 106.7 & 102.5 \\
\hline 21 & 25 & 1 & 3 & 25.4 & 1 & 3 & 101.6 & 100 & 100 \\
\hline 22 & 25 & 2 & 1 & 25.4 & 1.9 & 1 & 101.6 & 95 & 100 \\
\hline 23 & 25 & 3 & 10 & 25.3 & 3 & 9.8 & 101.2 & 100 & 98 \\
\hline 24 & 25 & 1 & 8 & 25.3 & 1 & 8.1 & 101.2 & 100 & 101.2 \\
\hline 25 & 25 & 2 & 6 & 25.2 & 2.1 & 6 & 100.8 & 105 & 100 \\
\hline 26 & 30 & 1 & 4 & 30.3 & 1 & 4.2 & 101 & 100 & 105 \\
\hline 27 & 30 & 2 & 2 & 30.3 & 2.1 & 2.1 & 101 & 105 & 105 \\
\hline
\end{tabular}


Kamal et al., Arch Pharm Sci ASU 4(2): 249-252

\begin{tabular}{cccccccccc}
\hline $\mathbf{2 8}$ & 30 & 3 & 0 & 30.1 & 3 & 0 & 100.3 & 100 & 100 \\
$\mathbf{2 9}$ & 30 & 1 & 9 & 30.2 & 1 & 9.1 & 100.7 & 100 & 101.1 \\
$\mathbf{3 0}$ & 30 & 2 & 7 & 30.3 & 2 & 7 & 101 & 100 & 100 \\
$\mathbf{3 1}$ & 3 & 3 & 5 & 3 & 3 & 4.8 & 100 & 100 & 96 \\
$\mathbf{3 2}$ & 3 & 1 & 3 & 3 & 1 & 3 & 100 & 100 & 100 \\
$\mathbf{3 3}$ & 3 & 2 & 1 & 3 & 2 & 1 & 100 & 100 & 100 \\
$\mathbf{3 4}$ & 3 & 3 & 10 & 3 & 3 & 10.1 & 100 & 100 & 101 \\
$\mathbf{3 5}$ & 3 & 1 & 8 & 3 & 1 & 8.1 & 100 & 100 & 101.2 \\
$\mathbf{3 6}$ & 23 & 2 & 6 & 23.1 & 2 & 6.2 & 100.4 & 100 & 103.3 \\
$\mathbf{3 7}$ & 23 & 3 & 4 & 23 & 3 & 3.8 & 100 & 100 & 95 \\
$\mathbf{3 8}$ & 23 & 1 & 2 & 23.2 & 1 & 2 & 100.8 & 100 & 100 \\
$\mathbf{3 9}$ & 23 & 2 & 0 & 23.1 & 2 & 0 & 100.4 & 100 & 100 \\
$\mathbf{4 0}$ & 23 & 2.5 & 10 & 23.2 & 2.4 & 10.1 & 100.8 & 96 & 101 \\
$\mathbf{4 1}$ & 23 & 0 & 8 & 23.3 & 0 & 7.9 & 101.3 & 100 & 98.7 \\
$\mathbf{4 2}$ & 12 & 1.5 & 6 & 12 & 1.5 & 6.1 & 100 & 100 & 101.7 \\
$\mathbf{4 3}$ & 12 & 2.5 & 4 & 12.1 & 2.5 & 4.1 & 100.8 & 100 & 102.5 \\
$\mathbf{4 4}$ & 12 & 1.5 & 0 & 12.1 & 1.5 & 0 & 100.8 & 100 & 100 \\
$\mathbf{4 5}$ & 12 & 2.5 & 5 & 12.1 & 2.4 & 4.7 & 100.8 & 96 & 94 \\
& & & & & & Mean & 100.46 & 100.26 & 99.91 \\
\end{tabular}

ANN; Artificial Neural Network - TICA; Ticagrelor - IRB; Irbesartan - HCT; Hydrochlorothiazide - RSD; Relative Standard Deviation

Table 3. Assay results for TICA, IRB and HCT in their laboratory made mixtures using the proposed ANN method

\begin{tabular}{|c|c|c|}
\hline \multirow[t]{2}{*}{$\begin{array}{l}\text { Ratio } \\
\text { TICA+IRB+HCT } \\
\mu \mathrm{g} / \mathrm{mL} \\
9: 1.5: 5\end{array}$} & \multicolumn{2}{|c|}{$\begin{array}{c}\text { Mean Recovery } \pm \text { SD }^{\mathrm{a}} \\
\text { RSD \% } \\
\text { Er } \%^{\mathrm{c}}\end{array}$} \\
\hline & HPLC $(230 \mathrm{~nm})$ & ANNs \\
\hline $\begin{array}{l}\text { TICA } \\
\text { Mean Recovery } \pm \text { SD }^{a} \\
\text { RSD \% }{ }^{b} \\
\text { Er \% }\end{array}$ & $\begin{array}{c}98.76 \pm 0.45 \\
0.45 \\
-1.01\end{array}$ & $\begin{array}{c}99.85 \pm 1.13 \\
0.45 \\
-1.01\end{array}$ \\
\hline $\begin{array}{l}* * \text { t-test } \\
* * \text { F-test }\end{array}$ & - & $\begin{array}{c}2.01 \\
6.3\end{array}$ \\
\hline $\begin{array}{l}\text { IRB } \\
\text { Mean Recovery } \pm \text { SD }^{a} \\
\text { RSD \% }{ }^{b} \\
\text { Er \%c }\end{array}$ & $\begin{array}{c}98.99 \pm 0.87 \\
0.87 \\
-1.01\end{array}$ & $\begin{array}{c}100.05 \pm 1.53 \\
0.87 \\
-1.01\end{array}$ \\
\hline $\begin{array}{l}* * \text { t-test } \\
* * \text { F-test }\end{array}$ & - & $\begin{array}{l}1.35 \\
3.09\end{array}$ \\
\hline $\begin{array}{l}\text { HCT } \\
\text { Mean Recovery } \pm \text { SD }^{a} \\
\text { RSD \% } \\
\text { Er \% }\end{array}$ & $\begin{array}{c}99.08 \pm 0.61 \\
0.61 \\
-0.92\end{array}$ & $\begin{array}{c}98.23 \pm 1.21 \\
0.61 \\
-0.92\end{array}$ \\
\hline $\begin{array}{l}* * \text { t-test } \\
* * \text { F-test }\end{array}$ & - & $\begin{array}{l}1.42 \\
3.93\end{array}$ \\
\hline
\end{tabular}


ANN; Artificial Neural Network - TICA; Ticagrelor - IRB; Irbesartan - HCT; Hydrochlorothiazide

${ }^{\mathrm{a}}$ Mean \pm SD for the five determinations; ${ }^{\mathrm{b}} \%$ Relative standard deviation; ${ }^{\mathrm{c}} \%$ Relative error

$* *$ Theoretical values of $\mathrm{t}-$ and $\mathrm{F}-$ at $\mathrm{P}=0.05$ are 2.13 and 6.93 , respectively

\subsubsection{Analysis of Spiked Plasma Samples}

Absorbance data of ternary mixture (full scan), in three spiked human plasma samples, was applied to the ANN calibration model. Each sample was scanned for three successive times, satisfactory results were obtained (Table 4).

\subsection{Conclusion}

As it is known, analysts tend to use linear calibration systems. On the other hand, nonlinear calibration models are necessary for the spectral quantitative analysis of complex pharmaceutical matrices due to small deviations from linearity, some interactions due to excipients or interfering components, and the need for high sensitivity. The proposed method used a feed-forward back propagation neural network to predict blood serum concentration levels of TICA, IRB, and HCT in spiked plasma samples. The results of the study show that the neural network has the predictive capability and able to accurately predict drug concentration levels in spiked human plasma making it interchangeable tools for effectively estimating concentration levels. In addition to accuracy, the neural network application has the advantage of producing results empirically, without the need for developing statistical prediction models.

Table 4. Assay results for TICA, IRB and HCT mixtures in spiked plasma samples using the proposed ANN method

\begin{tabular}{|c|c|c|c|c|c|c|c|c|}
\hline \multicolumn{3}{|c|}{$\begin{array}{c}\text { Concentration } \\
\text { Added } \\
\mu \mathrm{g} / \mathrm{mL}\end{array}$} & \multicolumn{3}{|c|}{$\begin{array}{c}\text { concentration found } \\
\mu \mathrm{g} / \mathrm{mL}\end{array}$} & \multicolumn{3}{|c|}{$\begin{array}{c}\text { Mean Recovery } \pm \mathrm{SD}^{\mathrm{a}} \\
\operatorname{RSD} \%^{\mathrm{b}} \\
\operatorname{Er} \%^{\mathrm{c}}\end{array}$} \\
\hline TICA & IRB & $\mathrm{HCT}$ & TICA & IRB & $\mathrm{HCT}$ & TICA & IRB & HCT \\
\hline 30 & 3 & 10 & 30.30 & 3.00 & 10.30 & $\begin{array}{c}101.00 \pm 1.01 \\
1.00 \\
1.00\end{array}$ & $\begin{array}{c}100.00 \pm 0.9 \\
0.90 \\
0.00\end{array}$ & $\begin{array}{c}103.00 \pm 1.00 \\
0.97 \\
3.00\end{array}$ \\
\hline 30 & 2.5 & 6 & 30.20 & 2.45 & 5.87 & $\begin{array}{c}100.70 \pm 0.85 \\
0.84 \\
0.70\end{array}$ & $\begin{array}{c}98.00 \pm 1.41 \\
1.44 \\
-2.00\end{array}$ & $\begin{array}{c}97.80 \pm 1.21 \\
1.23 \\
-2.20\end{array}$ \\
\hline 5 & 1 & 2 & 5.10 & 1.01 & 1.99 & $\begin{array}{c}102.00 \pm 0.55 \\
0.54 \\
2.00\end{array}$ & $\begin{array}{c}101.00 \pm 0.31 \\
0.31 \\
1.00\end{array}$ & $\begin{array}{c}99.50 \pm 0.81 \\
0.81 \\
-0.50\end{array}$ \\
\hline
\end{tabular}

ANN; Artificial Neural Network - TICA; Ticagrelor - IRB; Irbesartan - HCT; Hydrochlorothiazide

${ }^{a}$ Mean \pm SD for the five determinations; ${ }^{\mathrm{b}} \%$ Relative standard deviation; ${ }^{\mathrm{c}} \%$ Relative error

\section{List of Abbreviations}

ANN, Artificial Neural Network; TICA, Ticagrelor; IRB, Irbesartan; HCT, Hydrochlorothiazide; HNN, hidden neurons number; Lc, Learning coefficient; RMSEP, Root mean square error of prediction; MSE, Mean square error.

\section{Declarations}

\section{Availability of data and materials}

All data generated or analyzed during this study are included in this published article [and its supplementary information files].

\section{Competing interests}


The authors declare that they have no competing interests.

\section{Funding}

All laboratory requirements; instrumentation, reagents, and solvents were funded by Beirut Arab University, Lebanon.

\section{Authors' contributions}

A.A.G pointed out the idea of the assay, gave the plan of work, and revised the output data.

M.F.K controlled the mathematical manifestations, arranged the chemometric steps (practical and data handling), and wrote the final manuscript.

M. J. worked out all practical experiments and prepared for manuscript writing by summing up tables and figures.

\section{Acknowledgments}

This work has been supported by Beirut Arab University, Lebanon.

\section{REFERENCES}

1. Kiralj R, Ferriera M. The past, present, and future of chemometrics worldwide: Some etymological, linguistic, and bibliometric investigations. $\mathrm{J}$ Chemomet 2006;20:247-272. https://onlinelibrary.wiley.com/doi/abs/10.1002/ce m.1001

2. Wrecksin et al. Comparison of Chemometric Problems in Food Analysis using Non-Linear Methods. Molecules 2020;25:13, 3025. https://www.mdpi.com/1420-3049/25/13/3025

3. El Gindy A, Hadad GM. Chemometrics in Pharmaceutical Analysis: An Introduction, Review, and Future Perspectives. J AOAC Inter 2012;95:609-623.

https://pubmed.ncbi.nlm.nih.gov/22816252/

4. Miguel de la Guardia SG. Handbook of Green Analytical Chemistry. $1^{\text {st }}$ ed. New York: Wiley \& sons; $2012 . \quad$ http://download.ebookshelf.de/download/0000/5956/47/L-G-
0000595647- 0002363170. pdf

5. Hung Sung K. Decision making in Artificial Intelligence. J Korean Med Sci 2020; 6:35, 1. https://jkms.org/DOIx.php?id=10.3346/jkms.2020. 35.e1

6. Sutariya V, Groshev A, Sadana P, Bhatia D, Pathak Y. Artificial Neural Network in Drug Delivery and Pharmaceutical Research. The Open Bioinformatics Journal 2013;7(Suppl-1, M5):4962.

https://benthamopen.com/contents/pdf/TOBIOIJ/T OBIOIJ-7-49.pdf

7. Santos DL. FTIR Spectroscopy as a possible rapid tool to evaluate abiotic stress effects on pineapple by-products. Appl Sci 2019; 9: 4141. https://www.mdpi.com/2076-3417/9/19/4141

8. Maran JP, Sivakumar V, Thirugnanasambandham K, Sridhar R. ANN and Response Surface Methodology Modeling in Mass Transfer Parameters Prediction during Osmotic Dehydration of Carica Papaya L. Alexandria Engineering Journal 2013; 52:507-516. https://www.researchgate.net/deref/http $\% 3 \mathrm{~A} \% 2 \mathrm{~F} \%$ 2Fdx.doi.org\%2F10.1016\%2Fj.aej.2013.06.007

9. Darwish HW, Attia MI, Abdelhameed AS, Alanazi AM, Bakheit AH. Comparative ANNs with different Input layers and GA-PLS study for simultaneous spectrofluorimetric determination of melatonin and pyridoxine in the presence of melatonin's impurity. Molecules 2013; 18:974996. https://doi.org/10.3390/molecules 18010974

10. Tolle KM, Chen H, Chow HH. Estimating drug/plasma concentration levels by applying neural networks to pharmacokinetic data sets. Artificial Intelligence Lab, Department of MIS, University of Arizona, 2000; 30:139-152. https://doi.org/10.1016/S0167-9236(00)00094-4

11. Darwish HW. Application of smart spectrophotometric methods and artificial neural network for the simultaneous quantitation of Olmesartan Medoxamil, Amlodipine Besylate, and Hydrochlorothiazide in their combined pharmaceutical dosage form. Chemistry Central Journal 2013; 7:22. 
https://dx.doi.org/10.1186\%2F1752-153X-7-22

12. Dinc E, Üstundag Ö. Quantitative Analysis of Hydrochlorothiazide and Losartan Potassium in A Binary Mixture by Artificial Neural Network. FABAD J Pharm Sci 2010; 35:133-141. http://dergi.fabad.org.tr/pdf/volum35/issue3/133141.pdf

13. Elkady EF. Simultaneous Spectrophotometric determination of Diclofenac Potassium and Methocarbamol in a binary mixture using chemometric techniques and artificial neural networks. Drug Testing and Analysis 2011; 3:228233.

https://onlinelibrary.wiley.com/doi/pdf/10.1002/dta .216

14. Neutel MD. A Comparison of the Efficacy and Safety of Irbesartan/Hydrochlorothiazide Combination Therapy with Irbesartan Monotherapy in the Treatment of Moderate or Severe Hypertension in Diabetic and Obese Hypertensive Patients: A Post-Hoc Analysis Review.Postgraduate Medicine 2015;123,4: 126134 https://doi.org/10.3810/pgm.2011.07.2312

15. Dabrowski R. Use of antiplatelet and anticoagulant drugs in hypertension. European Society of Cardiology 2015; 13: 37. https://www.escardio.org/Journals/E-Journal-ofCardiology-Practice/Volume-13/use-ofantiplatelet-and-anticoagulant-drugs-inhypertension

16.Lacy CF, Armstrong LL, Goldman MP, Lance LL. Drug Information Handbook. $12^{\text {th }}$ ed. Lexi-Comp Inc, 2005.

17. RamakrishnaV.S. and Rambabu C. Visible Spectrophotometric Methods for the Determination of Irbesartan in pharmaceutical formulations. Int $\mathbf{J}$ of Pharmacy and Pharmaceutical Sciences 2012;4:86,87.https://www.researchgate.net/publica tion/289016051

18. Sahoo SK et al. Validated RP-HPLC Method for Simultaneous Estimation of Irbesartan and Hydrochlorothiazide in Tablet Dosage Form. Int J Pharma Res Health Sci 2017; 5 (5): 1419-23 http://www.pharmahealthsciences.net/pdfs/volume
5-issue52017/15.vol5-issue5-2017-MS-15464.pdf

19. Virani Petal. Irbesartan: A Review on Analytical Method and its Determination in Pharmaceuticals and Biological Matrix. Inventi Rapid-Pharm Analysis \& Quality Assurance 2014. http://inventi.in/journal/article/rapid/4/11216/phar m-analysis-quality-assurance/pi\#

20. Patel KR, Patel SA, Darji VC. Simultaneous Spectrophotometric Estimation of Irbesartan and Hydrochlorothiazide in tablets. Int Res J Pharm 2011;2:

202-207.

https://irjponline.com/admin/php/uploads/volissue $3 / 35 . p d f$

21. Raja B, Himasri P, Ramadevi B. RP-HPLC Method for the Simultaneous Estimation of Irbesartan and Hydrochlorothiazide in Pharmaceutical Dosage Form. Int. Res J Pharm App Sci 2012; 2(3):29-38. http://www.irjpas.com/File_Folder/Raja\%202938.pdf

22. Elshanawane AA, Abdelaziz LM, Kamal MM, Hafez HM. Quantitative determination of four angiotensin-II-receptor antagonists in presence of hydrochlorothiazide by a gradient technique HPLC in their pharmaceutical preparations. Journal of Liquid Chromatography \& Related Technologies 2013; $37: 171-186$. https://doi.org/10.1080/10826076.2012.738620

23. Vujić Z, Mulavdić N, Smajić M, Brborić J, Stankovic P. Simultaneous analysis of Irbesartan and Hydrochlorothiazide: An improved HPLC method with the aid of a chemometric protocol. Molecules 2012; 17: 3461-3474. https://doi.org/10.3390/molecules17033461

24. Peeyush J, Bhardwaj YR, Kishore D. A Liquid Chromatography-Tandem Mass Spectrometry based method for the Simultaneous Determination of Irbesartan and Hydrochlorothiazide in Human Plasma. Int J Drug dev and Res 2013;5:169-173. https://www.ijddr.in/

25. Hammouda MEA., El-enin MAA., El-sherbiny DT., El-was saw DR, El-ashy SM. Simultaneous Determination of Irbesartan and Hydrochlorothiazide in Pharmaceutical 
Preparations and Spiked Human Plasma Using Microemulsion Liquid. Inter $\mathrm{j}$ of $\mathrm{adv}$ in pharm res 2013;4:1944-1959.

26. Swamy GK, Kumar J, Rao JV. A validated reverse phase HPLC method for the simultaneous estimation of Irbesartan and Amlodipine in the pharmaceutical dosage form. World Journal of Pharmacy and Pharmaceutical Sciences 2014;3:996-1007.

27. Virani P, Sojitra R, Raj H, Jain V. Chromatographic method for Irbesartan and its combination with another drug. Journal of Critical Reviews 2015; 2:4-8.

28. Hapse SA, Wagh VS, Kadaskar PT, Dokhe MD, Shirsath AS. Spectrophotometric estimation and validation of hydrochlorothiazide in tablet dosage forms by using different solvents. Pharma Chemica 2012;4:10-14.

http://derpharmachemica.com/archive.html

29. Bhagwate S, Gaikwad NJ. Stability indicating HPLC method for the determination of Hydrochlorothiazide in the pharmaceutical dosage form. $\mathrm{J}$ of Applied Pharmaceutical Science 2013;3:88-92. DOI: 10.7324/JAPS.2013.30215

30. Bhatia R, Katoch S, Kumar D. Review Article Determination of hydrochlorothiazide and drugs in its combination by HPLC. Journal of Chemical and Pharmaceutical Research 2015;7:184-190. https://www.jocpr.com/abstract/determination-ofhydrochlorothiazide-and-drugs-in-its-combinationby-hplc-5948.html

31. Sivasubramanian L, Ks L. Spectrophotometric Multicomponent Analysis of Telmisartan, Hydrochlorothiazide, and Ramipril in Pharmaceutical Formulations By Chemometric Techniques. World Journal of Pharmacy and Pharmaceutical Sciences 2015; 4:536-550. https://www.researchgate.net/publication/2733175 81

32. Pandya D, Patel M, Ghediya R, Shah A, Khunt R. UV-Vis Spectrophotometric Assay determination of oral antiplatelet Ticagrelor drug in the pharmaceutical formulation: Application to content uniformity. J of Chem and Pharm Res
2016; $8: 316-321$. https://www.researchgate.net/publication/3035504 30

33. Sillen H, Cook MDP. Determination of Ticagrelor and two metabolites in plasma samples by liquid chromatography and mass spectrometry. J Chromatogr B Analyt Technol Biomed Life Sci 2010;878:2299-2306. https://doi.org/10.1016/j.jchromb.2010.06.018

34. Sillen H, Cook M, Davis P. Determination of unbound Ticagrelor and its active metabolite (ARC124910XX) in human plasma by equilibrium dialysis and LC-MS/MS. J Chromatogr B 2011;879:2315-2322. https://doi.org/10.1016/j.jchromb.2011.06.023

35. El Jamal MK, Gazy AA. Analysis of Three Cardiovascular Drugs in Their Ternary Mixture Using Green Analytical Methodology of Smart Spectrophotometric Methods And RP-HPLC Method. Int $\mathbf{J}$ of Pharmacy and Pharm Sci 2016;8:8, 243-50. https://innovareacademics.in/journals/index.php/ijp ps/article/view/12390.

36. El Jamal MK, Gazy AA. Selective H-point Standard Addition and Double Divisor Ratio Derivative Chemometric Methods For Determination of Ternary Mixture Of Cardiovascular Drugs. BAU Journal - Health and Wellbeing 2019;2: 1,9.

https://digitalcommons.bau.edu.lb/hwbjournal/vol2/iss $1 / 9$

37. ICH Harmonized Tripartite guideline, Validation of Analytical Procedures text and Methodology Q2 (R1) Current Step 4 version, Parent guideline dated 27 November (Complementary guideline on Methodology dated 6 November 1996 incorporated on November 20 Geneva.

38. Miller JN, Miller JC. Statistics and Chemometrics for Analytical Chemistry. 5th Aufl., London, Pearson Prentice Hall, 2005. 